\title{
Iman Molekularrak: informazio unitate txikienaren bila
}

Single Molecule Magnets: looking for the smallest information unit

Andoni Zabala-Lekuona*

Kimika Ez-organikoa, Donostiako Kimika Fakultatea (UPV/EHU)

LABURPENA: Ahalik eta informazio gehien ahalik eta espazio murritzenean gordetzea gizartearen gaur egungo beharra eta nahia da, aldi berean. Zentzu honetan teknologia dezente aurreratua badago ere, 1993. urtean Mn12-ac koordinazio konposatua aurkitu zenean sekulako aurrerapausoa eman zen. Izan ere, Iman Molekular (SMM, Single Molecule Magnet) deituriko konposatu hauek informazio unitatea molekula bakar batera murriztea ahalbidetzen dute. Ondorioz, material hauekin sortutako gailuek askoz ere potentzial handiagoa izango lukete. Lan honetan 1993. urtetik gaur arte emandako aurrerapauso garrantzitsuenak laburbiltzen dira.

HITZ GAKOAK: iman molekularrak, trantsizio metalak, lantanidoak, magnetismoa.

ABSTRACT: Nowadays, storing the highest possible amount of information in size reduced devices is one of important concerns of society. Even though this kind of technology is quite developed, the discovery of the Mn12-ac coordination compound in 1993 was considered a huge step. This is because Single Molecule Magnets (SMMs) represent the smallest information units. Therefore, new devices based on this kind of materials would enhance information storage capacity. In the present work, the most important and representative discoveries since 1993 have been summarized.

KEYWORDS: single molecule magnets, transition metals, lanthanides, magnetism.

* Harremanetan jartzeko / Corresponding author: Andoni Zabala Lekuona. Kimika Aplikatua Saila, Kimika Fakultatea, Euskal Herriko Unibertsitatea (UPV/EHU), Manuel Lardizabal Ibilbidea, 3 zenbakia, 20018, Donostia, Euskal Herria. - andoni. zabala@ehu.eus - https://orcid.org/0000-0002-4666-991X.

Nola aipatu / How to cite: Zabala Lekuona, Andoni (2019). «Iman Molekularrak: informazio unitate txikienaren bila»; Ekaia, 35 2019, 85-99. (https://doi.org/10.1387/ekaia.19692).

Jasoa: 14 maiatza, 2018; Onartua: 2 uztaila, 2018.

ISSN 0214-9001 - eISSN 2444-3255 / (c) 2019 UPV/EHU 


\section{SARRERA}

Gero eta informazio gehiago gorde nahi da urteak pasa ahala. Adineko pertsona gehienek oraindik ere paperean inprimatutako liburuak irakurtzen jarraitzen badute ere, gero eta ohikoagoak dira liburu elektronikoak. Lehen argazkiak errebelatzeko ohitura ere bazen, bizi osoan zehar ateratako argazkiak albumetan itsasten ziren, baina gaur egun ordenagailu edo disko gogorretan gorde ohi dira maiz. Egunerokotasuneko bi adibide besterik ez dira, baina hausnarketa txiki bat eginez gero, segituan egin daiteke elektronikoki gordetzen den informazioaren zerrenda amaigabea: klaseko apunteak, etxeko gastuen fakturak, filmak, gutunak, musika, egunkarietako artikuluak, eta abar. Ukaezina da denbora pasa ahala informazioa modu honetan gordetzeko beharrak gora egin duela, eta behar horri erantzunez sortu dira mota askotako gailuak azken urteetan.

70. hamarkadan merkaturatu ziren lehenengo disketeak. Hiru hamarkadako iraupena besterik ez zuten izan, 2000. urtean deskatalogatu baitziren. Hauei CD-ek eta DVD-ek, USB memoriek eta disko gogorrek jarraitu zieten. Hau da, epe laburrean lortu dira tamaina txikiko eta potentzial handiko gailuak. Merkaturatu ziren lehenengo gailuek baino mila milioi aldiz informazio gehiago gorde dezakete gaur egun edonoren eskura dauden disko gogor arruntek. Azken finean, honelako gailuek duten ahalmena barnean dituzten domeinu magnetikoetan oinarritzen da. Hauek magnetizazioa norabide berean orientatuta duten imanen agregazio independenteak dira, hau da, atomoen momentu magnetiko guztiak lerrokatuak daude. Domeinu magnetiko bakoitzak 1 edo 0 -ari (hizkuntza bitarraren oinarria) dagokion informazioa gorde dezake. Hortaz, espazio berean zenbat eta domeinu gehiago izan, orduan eta informazio gehiago gorde ahal izango da. Gaur egun, normalki, kobaltoan oinarritutako aleazioak erabiltzen dira. Hauek aleetan banatzen dira, non ale bakoitza domeinu independente bat den.

Hala ere, 1993. urtean materialen zientziak berpizkundea izan zuen. Gero eta domeinu txikiagoak diseinatzeko nahi horretan, Mn12-ac molekula (1. irudia) aurkitu zuen Sessoliren taldeak [1]. Ordura arte pentsaezina bazen ere, aurkikuntza hark informazio unitatea ale mikroskopikoetatik maila molekularreraino murrizteko aukera eskaintzen zuen. Beste era batera esanda, material bateko molekula bakoitza domeinu magnetiko bat izan daitekeela ondorioztatu zuten. 


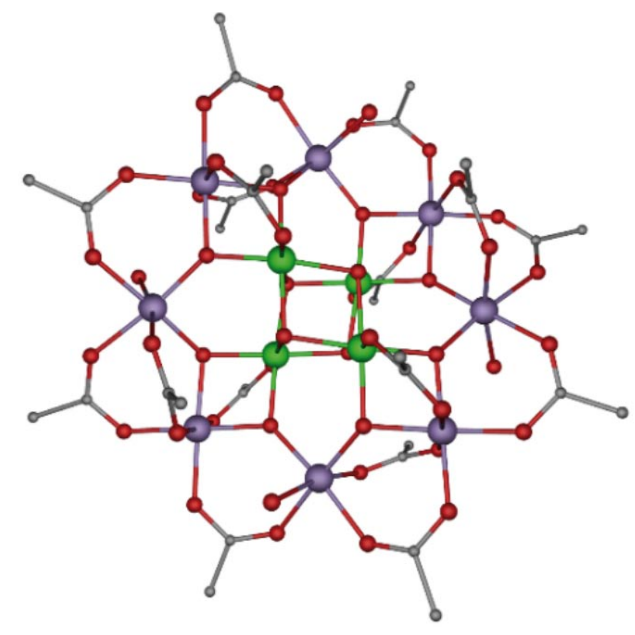

1. irudia. Mn12-ac molekula. Kolore kodea: manganeso (III), manganeso (IV), karbono eta oxigeno atomoak morez, berdez, grisez eta gorriz daude, hurrenez hurren [1].

\subsection{Iman Molekularrak, magnetizazioaren erlaxazio mantsoa}

Mn12-ac molekulak zentro metalikotzat oxidazio egoera ezberdineko manganeso ioiak ditu, $\mathrm{Mn}^{\mathrm{III}}$ (morea) eta $\mathrm{Mn}^{\mathrm{IV}}$ (berdea). Irudian ikusten den bezala, haien artean oxigeno zubi ezberdinak daude, $\mu-\mathrm{O}^{2-}$ motakoak nahiz $\mu$-OAc (azetato) motakoak. Hauen eraginez, interakzio antiferromagnetikoa ${ }^{1}$ gertatzen da oxidazio egoera ezberdineko zentro metaliko guztien artean eta, horregatik, $S=10$ spin balorea du konposatuak. Konposatu paramagnetiko guztiek dute $S \neq 0$ balioa, baina Mn12-ac bezalako molekulek aurrerago azalduko den berezitasun bat dute eta horri esker zero dimentsioko imanen edo Iman Molekularren (SMM, Single Molecule Magnet) kategorian sartzen dira. Koordinazio konposatu hauen ioiek anisotropia magnetikoa $(D)$ izan ohi dute, hau da, materialaren portaera magnetikoa desberdina da norabidearen arabera. Hala nola, $S=10$ oinarrizko egoera $21 m_{s}$ azpiegoeratan $\left(m_{s}=2 \cdot S+1\right)$ banatzen da (ikusi 2a. irudia), non $m_{s}= \pm 10$ egoerak diren energetikoki egonkorrenak. Azpiegoera hauek spinaren proiekzioari buruzko informazioa ematen dute, $m_{s}=-10$ egoerak spina $-z$ (edo «spin-down» egoera) noranzkoan orientatuta dagoela adieraziko du, eta $m_{s}=+10$ egoerak $+z$ (edo «spin-up») noranzkoan dagoela.

\footnotetext{
${ }^{1}$ Interakzioa antiferromagnetikoa denean, spinak antiparaleloki kokatzen dira eta elkar baliogabetzen dute $S$ balio txikia emanez; interakzioa ferromagnetikoa denean, spinak paraleloki kokatzen dira eta denen balioa batzen da $S$ balio altuak emanez.
} 
Gainerako azpiegoeren banatzea $D$-ren balioaren araberakoa da, besteak beste. Honek esan nahi duena da, spinaren proiekzioak $z$ ardatzean orientatuta egonda duela energia kosturik baxuena, hots, anisotropia magnetikoa erakusten duela (ikusi $2 b$. irudia).

a)

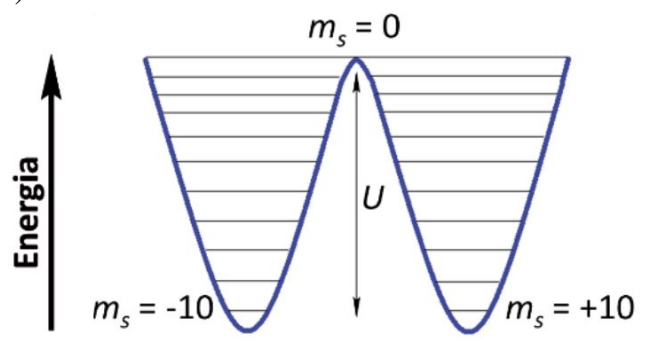

b)

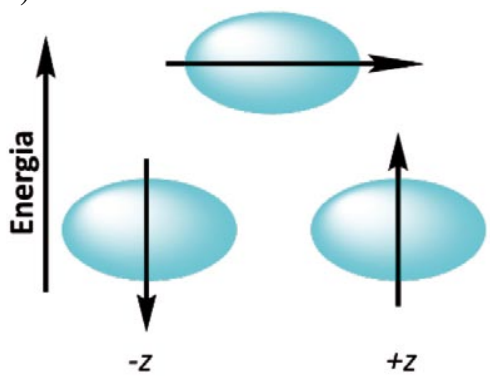

2. irudia. a) Mn12-ac molekularen $S=10$ spin egoerak anisotropiagatik $(D)$ jasaten duen azpiegoeren banatzea energiaren arabera; b) Energia baxueneko $\left(m_{s}= \pm 10\right)$ eta altueneko $\left(m_{s}=0\right)$ azpiegoeren spin proiekzioak.

Eremu magnetiko baten bitartez materialean dauden molekula guztien spinak $-z$ edo $+z$ noranzkoetan egotera behartu daitezke (3. irudia, erdialdean). Eremu magnetikoa kentzen bada, aldiz, materialak berriz ere hasierako egoerara itzultzeko joera izango du, hots, spin proiekzio erdiak $-z$ noranzkoan eta beste erdiak $+z$ noranzkoan egoteko joera izango dute, bi egoerak energetikoki maila berekoak baitira (3. irudia, ezkerraldean). Efektu hori berehala gertatzen da material paramagnetiko arruntetan. Iman molekularretan, berriz, ez da hain erraz gertatzen. Hasierako egoera $m_{s}=-10$ baldin bada, $m_{s}=+10$ egoerara pasa ahal izateko gainerako $m_{s}$ azpiegoera guztiak igaro behar ditu. Beste era batera esanda, barrera energetiko edo barrera termikoa $(U, 2$. irudia, ezkerraldean) igaro behar du. Azken finean, tenperatura da barrera hori gainditu edo ez baldintzatzen duena. Materiala blokeo-tenperatura $\left(T_{b}\right)$ baino tenperatura altuagoan badago, nahikoa energia izango du arazorik gabe orekara heltzeko. Tenperatura baxuagoan baldin badago, aldiz, ezin izango du barrera gainditu eta spinek $m_{s}=-10$ egoeran jarraituko dute blokeatuta (hortik dator blokeo-tenperatura), hau da, magnetizatuta jarraituko du eta erlaxazioa oso mantsoa izango da (3. irudia, eskuinaldean).

Hau da iman molekularren funtsa. Molekula bakar baten spina $-z$ edo $+z$ noranzkoan proiektatzen den momentuan hizkuntza bitarreko 1 edo 0 zenbakia ordezkatzen du, eta eremua kentzean magnetizazioa mantentzen jarraitzen duenez, informazioa gordetzeko gai da. Zein da orduan arazoa? Barrera termikoak $(U)$ oso handia izan behar duela tenperatura arruntetan (giro-tenperaturan, esaterako) materialak magnetizatuta jarraitzeko. Mag- 
netizazioa galtzen duen heinean informazioa galtzen du, jada ez baitu ez 1 ez 0 zenbakia ordezkatuko.

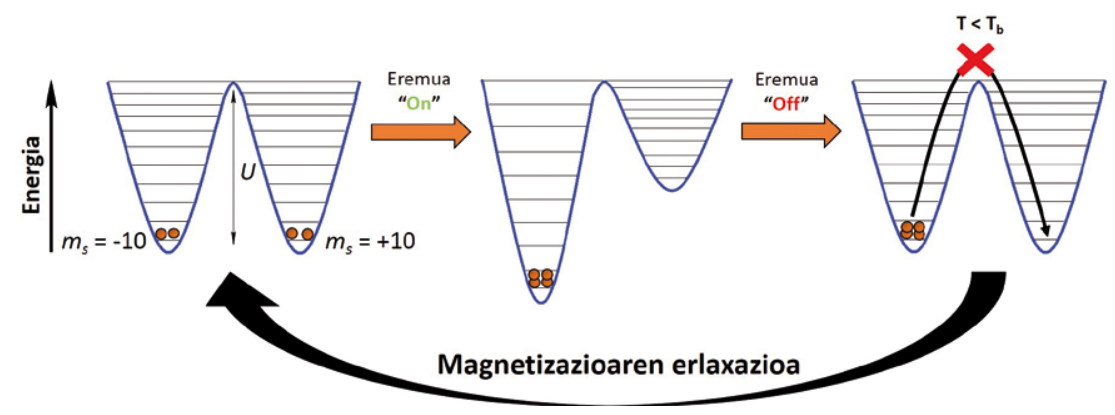

3. irudia. Ezkerraldea: molekulen spin proiekzioak orekan, erdiak $m_{s}=-10$ egoeran eta beste erdiak $m_{s}=+10$ egoeran. Erdialdean: eremu magnetiko baten bitartez molekula guztien spinak $m_{s}=-10$ egoeran egotera behartzen dira. Eskuinaldean: eremua kentzean sistemak orekara itzuli nahi du, baina ezin du lortu $\mathrm{T}<\mathrm{T}_{\mathrm{b}}$ delako.

\section{Mn12-ac KONPOSATUAREN ONDORENGO URTEAK}

\subsection{Trantsizio metalen klusterrak}

Iman molekularren diseinurako manganesoa aukera egokia zela zirudien eta haren oxidazio egoera ezberdineko espezieen artean, $\mathrm{Mn}^{\mathrm{III}}$ ioia bereziki egokia dela pentsatu izan da. Magnetizazioaren erlaxazioa saihesten duen barrera termikoaren ekuazioa honela definitzen da spin osoa eta spin erdi-osoa duten konposatuentzat, hurrenez hurren:

$$
\begin{array}{cc}
U=S^{2} \cdot|D| & \text { 1. ekuazioa } \\
U=\left(S^{2}-1 / 4\right) \cdot|D| & \text { 2. ekuazioa }
\end{array}
$$

Barrerak spinaren balioarengan duen dependentzia koadratikoa dela eta, hainbat eta hainbat ikerketa taldek hartutako bidea nahiko intuitiboa izan zela pentsa daiteke. Spin balio altuko kluster metalikoak (hainbat zentro metaliko dituzten konposatuak) sintetizatzea lortuz gero, barrera termikoa ere altua izatea espero zen. Esan bezala, $\mathrm{Mn}^{\mathrm{III}}$ ioia hautagai ona da, spin altukoa denean desparekatutako lau elektroi baititu. Horrez gain, anisotropia balio altua eman diezaioke molekulari Jahn-Teller distortsioen bitartez (fenomeno honek $z$ ardatzeko estekatzaileak urrundu nahiz gerturatzea eragin dezake sistema egonkorragoa izan dadin), eta honen ondorioz $m_{s}$ azpiegoerak oinarrizko egoeratik ondo banatuak egongo dira $U$-ren balioa handituz. 
Dena den, zentro metaliko anitzeko konposatu bat sintetizatzeak ez du esan nahi spin totalak balio altua izango duenik. Metalen arteko interakzioak ferromagnetikoak nahiz antiferromagnetikoak (Mn12-ac konposatuan gertatzen den bezala) izan daitezke eta ez dira ausazkoak izaten. Faktore asko dira fenomeno hau baldintzatzen dutenak, esate baterako hauek: metal-estekatzaile-metal angeluak, distantziak eta estekatzaile motak [2]. Jakina da azida $\left(\mathrm{N}_{3}{ }^{-}\right)$estekatzaileek, adibidez, interakzio ferromagnetikoak eman ohi dituztela [3]. Hain zuzen, Powell-en taldea jakintza honetaz baliatu zen. Hainbat zentro metalikotara koordina daitekeen estekatzaile bat (2,6-bis(hidroximetil)- $p$-kresola, $4 a$. irudia), sodio azida gatza eta manganesoa erabiliz 19 ioi metaliko dituen koordinazio konposatua sintetizatu zuten (4b. irudia) [4]. Ikus daitekeen bezala, konposatuak bi manganeso espezie ezberdin ditu barnean, $\mathrm{Mn}^{\mathrm{II}}$ (urdin argia) eta $\mathrm{Mn}^{\mathrm{III}}$ (lila).

a)<smiles>Cc1cc(CO)c(O)c(CO)c1</smiles>

b)

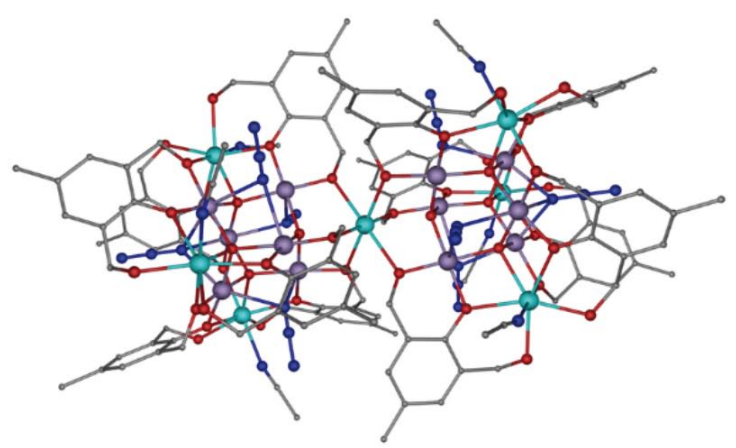

4. irudia. a) Powell-en taldeak erabilitako estekatzailea: 2,6-bis(hidroximetil)-pkresola; b) 19 zentro metalikoz osatutako klusterra. Kolore kodea: manganeso (II), manganeso (III), karbono, nitrogeno eta oxigenoa urdin argiz, lilaz, grisez, urdin ilunez eta gorriz daude, hurrenez hurren [4].

Estrategia honek emaitza gazi-gozoak eman zituen. Lotutako metalen arteko interakzio edo akoplamendua ferromagnetikoa zela ondorioztatu zuten. Hori gutxi ez, eta ordura arteko spin altueneko sistema zela ohartu ziren; izan ere, $S=83 / 2$-ko balioa zuen (spin altuko $\mathrm{Mn}^{\mathrm{III}}$ konposatu monometaliko batek $S=2 \mathrm{du}$, ideia bat egiteko). Barrera termikoak spinarekiko duen menpekotasun koadratikoak baikortasunerako bidea zabaltzen bazuen ere, anisotropia balioa oso txikia zuenez, spin totalaren balioak influentzia gutxi zuela ikusi zen. Hori da konposatu honi gertatzen zaiona. Anisotropia $(D)$ balio oso txikia duenez, haren barrera termikoa hain da baxua, ia neurgaitza baita. Ondorioz, kontzeptualki eta kimikoki lorpen handia izan bazen ere, material honen aurkikuntzak erabilpen errealari begira ez du potentzialik iman molekularren alorrean. 


\subsection{Anisotropia faktore kritiko}

Azken konposatu polinuklear honekin gertatutakoa, dena den, ez da kasu bakana izan. Beste hainbat ikerketa-talde ere aritu izan dira mota honetako koordinazio konposatuak ikertzen [5] eta, orokorrean, ondorio berera iritsi dira. $\mathrm{Mn}_{6}$ [6] eta $\mathrm{Fe}_{19}$ [7] sistemetan $D=-0,43 \mathrm{~cm}^{-1}$ eta $D=-0,035 \mathrm{~cm}^{-1}$ balioak lortu zituzten. Lehenengoaren kasuan $S=12$ izanik, 1. ekuazioa aplikatuz barrera termikoaren balioa $U=62 \mathrm{~cm}^{-1}$ da. Lehen aipatutako Jahn-Teller distortsioa duten ohiko $\mathrm{Mn}^{\mathrm{III}}$ konposatu mononuklearrek $D=-4,5 \mathrm{~cm}^{-1}$ inguruko balioa izan ohi dute, $\mathrm{Mn}_{6}$ konposatuak baino 10 aldiz eta $\mathrm{Fe}_{19}$ konposatuak baino 100 aldiz handiagoa. Zer esan nahi du honek? Zentro metaliko bakar batekin dagoeneko $U=18 \mathrm{~cm}^{-1}$-ko barrera lor daitekeela $\left(U=S^{2} \cdot|D|=2^{2} \cdot|-4,5|=18 \mathrm{~cm}^{-1}\right)$. Dudarik gabe, efektu honen ezagutza mugarria izan da iman molekularren diseinua ikertzeko garaian. Izan ere, 1. eta 2. ekuazioak zalantzan jartzea eragin du.

Hori gutxi ez, eta Neese eta lankideek 2011. urtean frogatu zuten lehenago begi-bistan geratzen ari zena [8]. Barrera termikoa definitzen duten ekuazioek ezkutatu egiten dute $S$ eta $D$-ren arteko lotura. Beste informaziorik izan gabe bi aldagaiak independenteak direla pentsa daiteke, baina hori ez da horrela. Haien lanean ageri diren ekuazio fisikoek ondorioztatzen dute $D$ eta $S^{2}$ aldagaiak alderantziz proportzionalak direla. Beraz, kimikarien ikuspuntutik, spinaren balioa areagotzen saiatu ahala anisotropiaren balioa murriztea eragingo da. Gauzak honela, Mn12-ac konposatuaren ondorengo lehen urteak kluster metalikoen diseinuan eta ikerkuntzan igaro ondoren, anisotropiak garrantzia hartu zuen eta joerak aldatu egin ziren.

\section{LANTANIDOEN AROA}

\subsection{Lehen erreferentziak}

Trantsizio metalez osatutako SMMak aztertzen jarraitzen bada ere, 2003. urtean Ishikawaren taldeak beste pauso garrantzitsu bat eman zuen. Lur-arraro edo lantanidoetan oinarritutako lehen iman molekularra deskribatu zuten (5. irudia) [9]. Lehenago Koikeren taldeak [10] argitaratu bazuen ere irudian ikusten den neodimiozko konposatuaren kristal egitura, propietate magnetikoak Ishikawaren taldeak ikertu zituen. Koordinazio konposatu kationikoa da eta ftalozianina estekatzaileak axialki (goitik eta behetik) koordinatzen zaizkio zentro metalikoari, sandwich konformazioa emanez.

Esan bezala, aurkikuntza interesgarria izan zen. Izan ere, urrun geratzen da $\mathrm{Mn}_{6}$ konposatuaren $62 \mathrm{~cm}^{-1}$-eko barrera termikoa, terbiozko ( $\left.\mathrm{Tb}^{\mathrm{III}}\right)$ konposatu honen analogoak $230 \mathrm{~cm}^{-1}$-eko barrera baitu. Gutxienez bi ondorio dira azpimarratzekoak: a) barrera termikoaren balioa lehen aipatutako 
konposatuena baino askoz ere altuagoa da eta b) zentro metaliko bakar bat nahikoa da hori lortzeko, konposatu mononuklearrekin ere lor baitaitezke barrera termikoaren balio altuak.

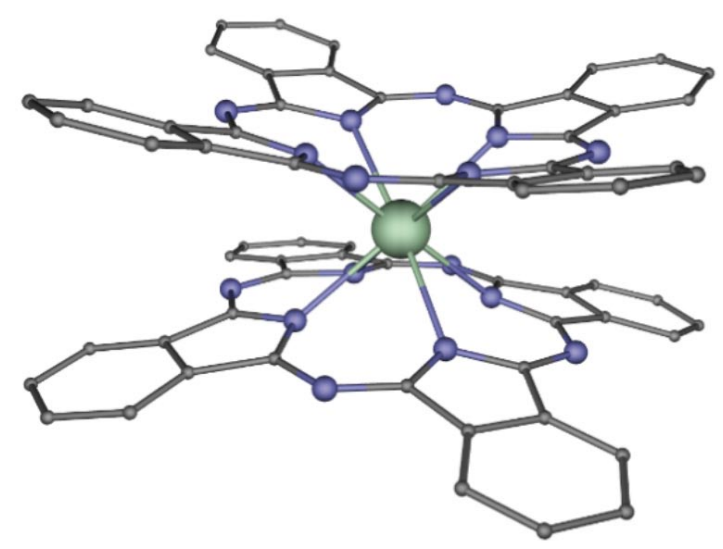

5. irudia. Koikeren taldeak argitaratutako neodimiozko sandwich motako konposatua, ondoren Ishikawaren taldeak terbiozko analogoa sintetizatzeko oinarritzat erabili zuena. Kolore kodea: neodimio (III), nitrogeno eta karbonoa berdexkaz, lilaz eta grisez daude, hurrenez hurren [10].

Zergatik ote? Lantanidoz osatutako konposatu guztiekin gertatzen ez bada ere, behin eta berriz aipatu den anisotropian du oinarria. Trantsizio metalen aldean, lantanido batzuek (aurrerago ikusiko den bezala $\mathrm{Tb}^{\mathrm{III}}$, $\mathrm{Dy}^{\mathrm{III}}$ eta Er ${ }^{\mathrm{III}}$-ak, besteak beste) berezkoa dute anisotropia. $4 \mathrm{f}$ orbitaletako balentzia elektroiak eta haien proiekzioa ezin da $m_{s}$ zenbaki kuantikoekin adierazi, zehaztasun gehiagotan sartzea merezi ez badu ere, spin-orbita akoplamendua oso handia baita. Akoplamendu hau da anisotropia handien erantzule. Efektu honek $m_{j}$ zenbaki kuantikoen erabilera behartzen du. Kontzeptualki ulertzeko, $m_{s}$ balioen esanahi antzekoa dute, baina fisikoki balentzia elektroiak era egokian deskribatzeko beharrezkoa da modu hone$\tan$ egitea. Adibide gisa, aipatu da Mn12-ac konposatuaren $S=10$ egoerak $m_{s}=2 \cdot S+1$ azpiegoera dituela $\left(m_{s}= \pm 10, \pm 9, \pm 8, \pm 7, \pm 6, \pm 5, \pm 4, \pm 3, \pm 2\right.$, \pm 1 eta 0$)$, DyIII ioi libreak, bestalde, $J=15 / 2(J$, spina + spin-orbita akoplamendua kontuan hartzen dituen terminoa) oinarrizko egoera $m_{j}=2 \cdot J+1$ azpiegoeratan banatua du $\left(m_{j}= \pm 15 / 2, \pm 13 / 2, \pm 11 / 2, \pm 9 / 2, \pm 7 / 2, \pm 5 / 2, \pm 3 / 2\right.$ eta $\pm 1 / 2$ ). Trantsizio metalekin gertatzen den antzera, gakoa azpiegoera horien arteko energia-diferentzia handia izatean datza, honela lortuko baita barrera termikoaren balioa handia izatea. 


\subsection{Nola landu lantanidoen potentzial guztia?}

Azpiegoerak ordena ezberdinetan bana daitezke eta hori estekatzaileek mugatzen dute. Kimikarien lana estekatzaile egokien diseinuan datza, hauek zentro metalikora koordinatzen direnean gertatuko baita $m_{j}$-en banatzea. Banatze horrek bi ezaugarri izango ditu: batetik, oinarrizko egoera bikoitz bat $\left( \pm m_{j}\right.$ egoera bat) definituko da $m_{j}$ egoera posible guztien artean, eta, bestetik, eragindako anisotropiaren araberako energia-diferentzia egongo da azpiegoeren artean. Bi faktore horiek determinatuko dute, azkenean, barrera termikoaren balioa. Hortaz, oinarrizkoa da edozein proba egin aurretik erabiliko diren materialak zeintzuk diren definitzea. Long eta Rinehart-ek azaltzen duten bezala, lur-arraro bakoitzak bere hodei elektronikoa du, ia denak anisotropikoak, hau da, ez dute esfera perfektuaren forma, baina denak zertxobait desberdinak beren artean [11]. Hori dela eta, erabilitako zentro metalikoaren arabera diseinatu beharko dira estekatzaileak.

Kontzeptu hau ondo ulertzeko, atomoen hodei elektronikoak, sinplifikatuz, bi motatan sailkatzen dira: oblatu formakoak eta prolatu formakoak (6. irudia, ezkerraldean). Iman molekular bat diseinatzeko garaian, helburua izanik oinarrizko egoeratzat balio altueneko $m_{j}$ azpiegoerak $\left(m_{j}= \pm 15 / 2\right.$ Dy III-ren kasuan) eta $D$ balio altuak lortzea (modu honetan lortuko baita barrera termiko altua), hodei elektronikoaren berezko forma egonkortzea lortu behar da. Hodei elektronikoan elektroiak daude, eta estekatzaileek ere karga elektronikoa ematen diote zentro metalikoari. Ondorioz, aldarapen elektronikoak gertatuko dira hodeia osatzen duten balentzia elektroi eta estekatzaileen elektroien artean. Kontzeptualki sinplea den kontsiderazio honetan oinarrituz lor daiteke planteatutako helburua. Horrela, oblatu itxurako metalen kasuan (DyIII ioia, esaterako), estekatzaileak modu axialean kokatuz (6. irudia, goiko aldea) hodei elektronikoa plano ekuatorialean zabaltzea eragingo da, berezkoa duen forma egonkortuz eta anisotropia indartuz. Prolatu itxurako ioietan (ErIII ioia, adibidez), aldiz, kontrakoa gertatzen da. Komenigarriena estekatzaileak plano ekuatorialean kokatzea da, modu honetan hodei elektronikoa axialki luzatzea eragingo baita, berriz ere anisotropia indartuz.

Dena den, erraza badirudi ere, beti ez da espero dena gertatzen, eta alderantzizkoa ere gerta daiteke (6. irudia, beheko aldea). Prolatu forma duen ioi bati estekatzaileak modu axialean koordinatuz gero, estekatzaileek zapaldu egingo dute hodei elektronikoa eta forma esferikoa hartzera bultzatu, hots, berezkoa duen anisotropia deuseztatuko diote. Bada, oblatu ioiekin efektu berbera emango da estekatzaileak plano ekuatorialean koordinatzen diren momentuan.

Dagoeneko aurretik azaldu den terbiozko konposatuari erreparatuz, 6. irudiko goiko efektua gertatzen dela ikus daiteke. Sandwitch motako 
konposatu honetan ftalozianina estekatzaileak goitik eta behetik lotzen zaizkio ioi metalikoari, hau da, modu axialean koordinatzen dira. $\mathrm{Tb}^{\mathrm{III}}$ ioiak oblatu formako hodei elektronikoa duenez, koordinazio ingurune egokia ematen da bere propietate magnetikoak indartzeko eta, ondorioz, barrera termiko altuko iman molekularra sortzeko.
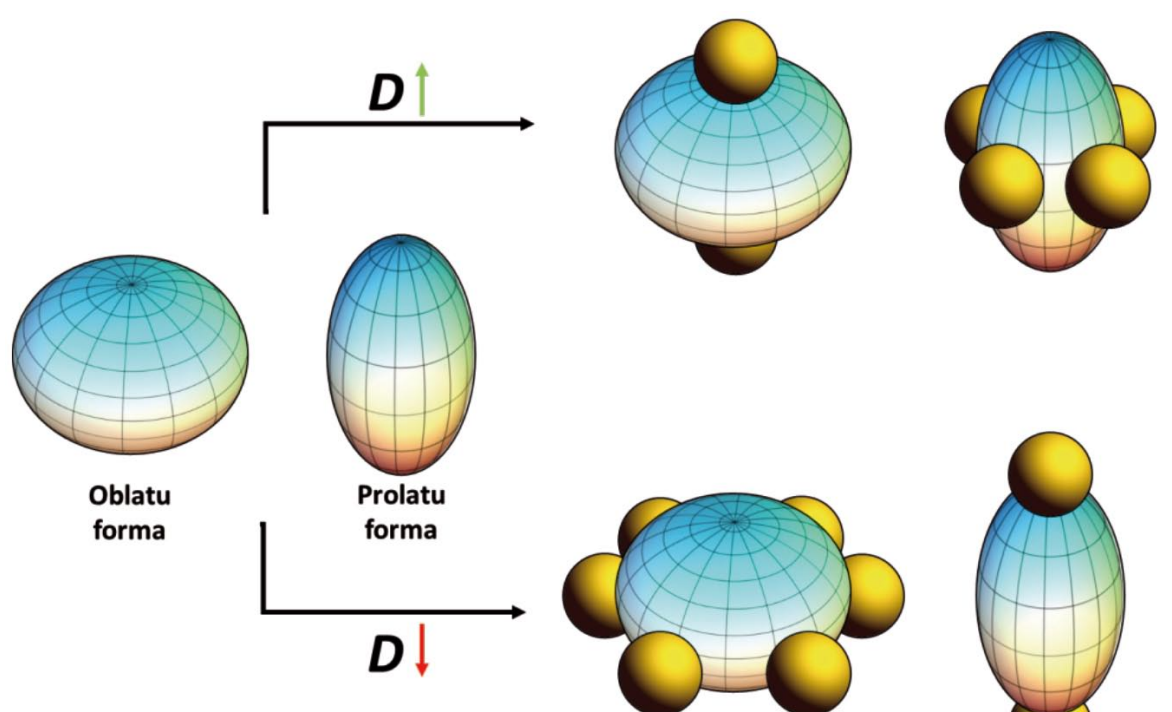

6. irudia. Ezkerraldean: oblatu eta prolatu motako hodei elektronikoak. Eskuin goiko aldea: kasu bakoitzean anisotropia balioa indartzeko estekatzaileek hartu behar duten posizioa. Eskuin beheko aldea: kasu bakoitzean anisotropia balioa gutxitzea eragingo duen estekatzaileen posizioa.

Esan bezala, kimikariek, ezertan hasi aurretik, erreaktiboak zeintzuk izango diren definitu ohi dute. Orri batean idazten da helburua zein den eta espekulatu edo aurresan ohi da zer molekula sortuko den erabilitako materialekin. Dena den, kimika oso apetatsua da askotan eta espero dena eta lortzen dena oso urrun egon daitezke bata bestetik. Hala eta guztiz ere, kimikari on bat beti da gai duen horri zuku gehiago ateratzeko. Horren adibide egokia da Murugesuren taldeak ikertutako 7. irudiko ezkerreko konposatua [12]. DyIII-zko koordinazio konposatu dinuklear honek bi estekatzaile mota ditu: $\mathrm{L}^{2-}$ estekatzaile nagusia eta acac $^{-}$osagarria. Metal zentrala oblatu itxurakoa izanik, estekatzaileak axialki edukitzea da egokiena, baina konposatu honetan ez da horrela gertatzen. Ondorioz, propietate magnetikoak aztertzeko garaian ez da harritzekoa $11 \mathrm{~cm}^{-1}$-eko barrera termiko txikia izatea. 
Dena den, estekatzailean aldaketa txiki batek propietateetan aldaketa handiak eragin ditzakeela frogatu zuten. Plano ekuatorialean koordinatuta dituen $\mathrm{acac}^{-}$estekatzaileetako oxigeno atomoek dentsitate elektronikoa ematen diete ioi metalikoei. Honek anisotropia murriztea dakar, aldarapen elektronikoek esfera itxura hartzera bultzatuko baitute Dy III ioia (6. irudian beheko aldean gertatuko den bezala). Honen aurrean, Murugesuren taldeak ideia bikain bat izan zuen: dentsitate elektronikoa ematen duten oxigeno atomoei, hain zuzen, dentsitatea kentzea. Nola? Acac ${ }^{-}$anioiaren $-\mathrm{CH}_{3}$ taldeak $-\mathrm{CF}_{3}$ taldeekin ordezkatuz (7. irudia, eskuinean). Fluorra elementu elektronegatiboa da, hots, dentsitate elektronikoa erakartzen du. Hori dela eta, koordinatuta dauden oxigeno atomoei emaile izaera gutxitzen dienez, plano ekuatorialean konposatu berriak duen karga elektronikoa, jada, ez da hain handia eta anisotropia indartzen da. Horrela, $11 \mathrm{~cm}^{-1}$-eko barrera izatetik $76 \mathrm{~cm}^{-1}$-eko barrera izatera pasatzen da konposatua.

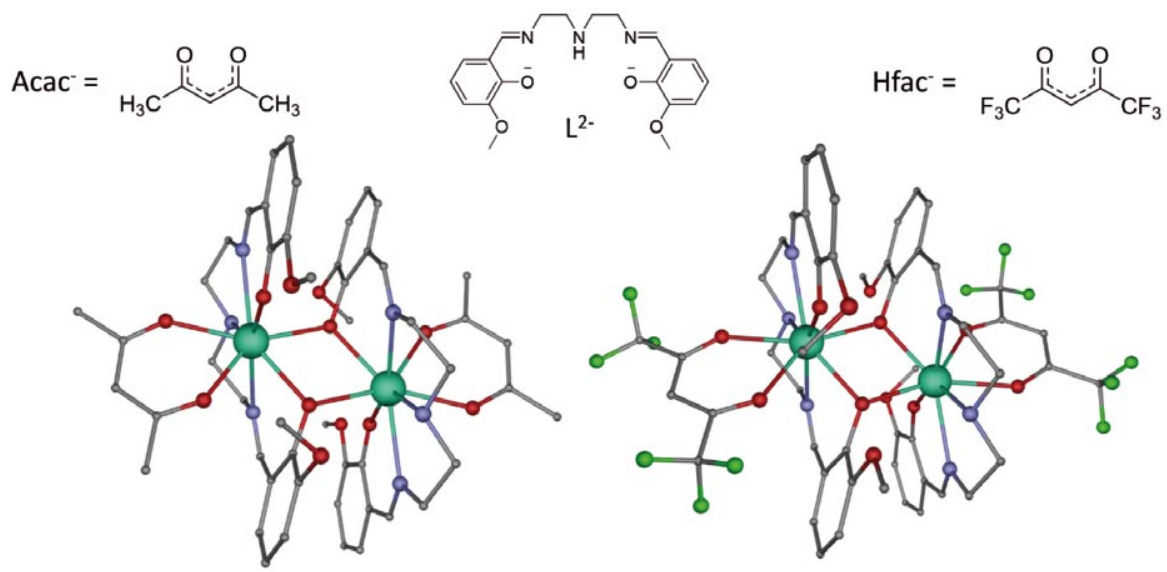

7. irudia. Goiko aldean erabilitako estekatzaileak: $\mathrm{Acac}^{-}=$azetilazetonatoa; $\mathrm{L}^{2-}=$ estekatzaile nagusia; $\mathrm{Hfac}^{-}=$hexafluoroazetilazetonatoa. Ezkerrean beheko aldean: estekatzaile nagusi, acac $^{-}$eta disprosioz osatutako koordinazio konposatu dinuklearra. Eskuinean beheko aldean: estekatzaile nagusi, hfac- eta disprosioz osatutako koordinazio konposatu dinuklearra. Kolore kodea: disprosio (III), karbono, nitrogeno, fluor eta oxigenoa turkesaz, grisez, lilaz, berdez eta gorriz daude, hurrenez hurren [12].

Azken adibide honek erakusten du portaera magnetikoaren konplexutasuna. Konposatu batean aldaketa txiki batek eragin handia erakuts dezake propietateetan. Kontua izaten da mesedegarria den aldaketa zein izango den hautematea. 


\section{AZKEN AURKIKUNTZAK}

Aipatutakoez gainera, aurrerapauso garrantzitsu asko eman dira azken urteotan. Dudarik gabe, hodei elektronikoen araberako diseinua egin ahal izateak asko errazten dio lana kimikariari, baina oraindik ere faktore asko daude barrera termikoa eta iman portaera bera baldintzatzen dutenak eta ondo ezagutzen ez direnak. Gainera, materialaren dimentsioak maila molekularreraino jaisten direnean, hain ezagunak ez diren fenomenoak ageri ohi dira, tunel kuantikoa (QTM, Quantum Tunneling of the Magnetization), esaterako.

Aurretik aipatu den bezala, materialaren spina eremu magnetiko bi$\operatorname{dez}-z$ noranzkoan orientatu ondoren, kanpoko eremua kenduz gero, spinek orekara itzultzeko joera izango dute (8. irudia). Tenperatura $(\mathrm{T})$ blokeo tenperatura $\left(T_{b}\right)$ baino txikiagoa bada, hori ezin dela gertatu adierazi da, baina ez da beti horrela izaten. Tamaina nanoskopikoko molekula hauetan tunel kuantikoa gerta daiteke, hau da, barrera termikoa gainditu gabe $-z$ egoeratik $+z$ egoerara pasa daitezke spinak inongo gastu energetikorik gabe. Ondorioz, magnetizatuta dagoen materialak magnetizazio guztia gal dezake efektu honen bidez, hots, informazioa galtzen du.

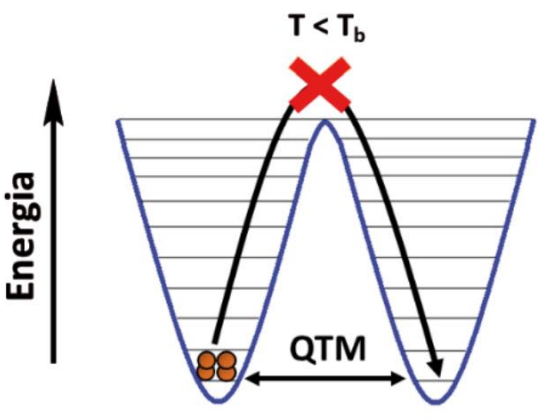

$M \neq 0$

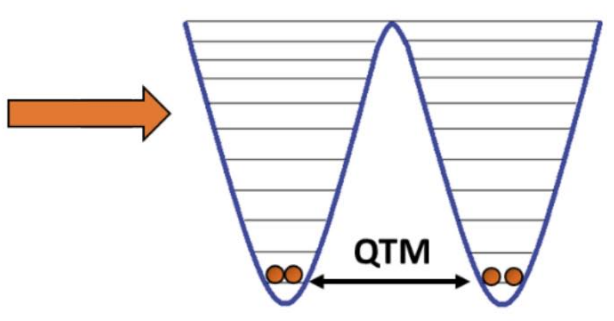

$\mathbf{M}=\mathbf{0}$

8. irudia. Maila bereko azpiegoeren artean gertatu ohi den tunel kuantikoa (QTM).

Teknika edo estrategia askotarikoak ezagutzen dira efektu hau gerta ez dadin, baina oraindik ere guztiz ezagutzen eta ulertzen ez den fenomeno bat da. Bestalde, magnetizazioaren erlaxazioa beste modu batzuetara ere gerta daiteke eta, pixkanaka, gero eta mekanismo ezagunagoak dira.

Hala ere, oraindik eguneroko aplikaziora begira nahiko urrun dagoen teknologia dela aipatu beharra dago. Izan ere, ikertzen diren konposatuek iman portaera oso tenperatura baxuetan erakusten dute, $10 \mathrm{~K}\left(-263^{\circ} \mathrm{C}\right)$ inguruan. Honek esan nahi duena da, material honek bere funtzioa bete ahal izateko izugarri jaitsi behar dela tenperatura eta honek aplikazioei begira ez 
du konpentsatzen. Material hauek sekulako abantailak dakartzaten arren, martxan jarri ahal izateko tenperatura $10 \mathrm{~K}$-etan mantendu behar bada, tenperatura hori mantentzen gastatu beharreko energia (beste hitz batzuetan, dirua) hainbesterainokoa da, non planteatu ere ezin den egin.

Gaur egun ezagutzen den iman molekularrik eraginkorrena Mills-en taldeak pasa den abuztuan Nature aldizkarian argitaratutako disprosiozenoa da [13] (9. irudia; c) konposatua). Aurretik 2016. urtean zeresan handia eman zuten disprosiozko bi konposatu nahiko antzekoak argitaratu ziren, biak geometria berekoak [14]: bipiramide pentagonala (9. irudia; a) eta b) konposatuak). Lehenak $14 \mathrm{~K}$-eko tenperaturan aurkezten ditu iman molekular propietateak, bigarrenak, aldiz, $20 \mathrm{~K}$-etan. Tenperatura horiek huskeria diruditen arren, sekulako aurrerapausoak izan dira magnetismoaren arlo honetan. Hala ere, disprosiozenoak marka guztiak apurtu ditu, $60 \mathrm{~K}$-eko tenperaturaraino erakusten baitu esperotako iman portaera. Oraindik konposatu hauek tenperatura baxuetan funtzionatzen badute ere, pixkanaka nitrogeno likidoaren tenperaturara hurbiltzen ari da teknologia hau; beraz, helburua gero eta gertuago dagoela esan daiteke.

a)

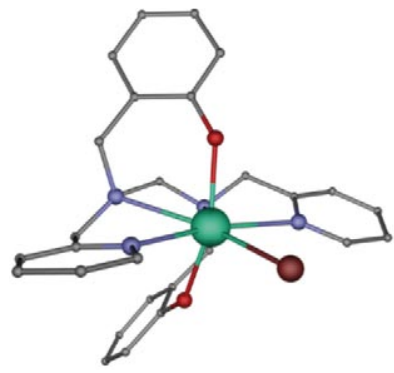

b)

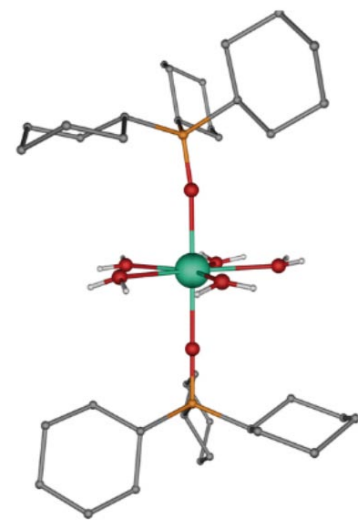

c)

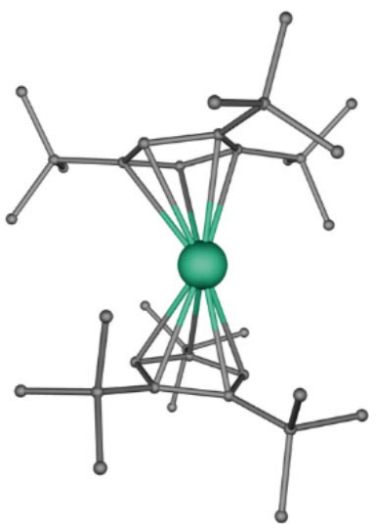

9. irudia. a) $14 \mathrm{~K}$ arte iman molekularren propietateak aurkezten dituen konposatu mononuklearra [14a]; b) $20 \mathrm{~K}$ arte iman molekularren propietateak aurkezten dituen konposatu mononuklearra [14b]; c) Gaur egun ezagutzen den iman molekularrik eraginkorrena, $60 \mathrm{~K}$ arte [13]. Kolore kodea: disprosio (III), karbono, nitrogeno, bromo, fosforo, hidrogeno eta oxigenoa turkesaz, grisez, lilaz, marroiz, laranjaz, txuriz eta gorriz daude, hurrenez hurren.

\section{ETORKIZUNARI BEGIRA}

1993. urtetik gaur arte magnetismo molekularrak sekulako aurrerapausoak eman ditu. Mn12-ac molekula aurkitu zen unetik, kimikarien joerak, 
estekatzaileen diseinuak, teknikak eta ikuspuntuak, besteak beste, ikaragarri aldatu dira. Mundu nanoskopiko hau inguratzen duten fenomeno kuantikoen ezagutza gero eta garatuagoa dago eta, dagoeneko, ia nitrogeno likidoaren tenperaturan lan egiteko gai den materiala aurkitu da. Dena den, oraindik ere guztiz ezagunak ez diren fenomeno asko daude lantzeke arlo honetan eta datozen urteetan, seguru, beste hainbat aurrerapauso eman ahal izango dira.

\section{ESKER ONAK}

Eskerrak eman behar dizkiot Eusko Jaurlaritzari ikertzaile ez doktoreen prestakuntzarako doktoratu aurreko laguntza emateagatik eta Euskal Herriko Unibertsitateari ikerkuntza proiektuen finantzaketagatik (GIU 17/013).

\section{BIBLIOGRAFIA}

[1] SESSOLI, R., TSAI, H.-L., SCHAKE, A.R., WANG, S., VINCENT, J.B., FOLTING, K., GATTESCHI, D., CHRISTOU, G. eta HENDRICKSON, D.N. 1993. «High-spin molecules: [Mn12O12(O2CR)16(H2O)4]». Journal of the American Chemical Society, 115, 1804-1816.

[2] RUIZ, J., MOTA, A.J., RODRÍGUEZ-DIÉGUEZ, A., OYARZABAL, I., SECO, J.M. eta COLACIO, E. 2012. «Rational design of ferromagnetic coupled diphenoxocarboxylate triply bridged dinuclear nickel(II) complexes: orbital countercomplementarity of the bridging ligands». Dalton Transactions, 41, 14265-14273.

[3] PAPAEFSTATHiou, G.S., ESCUER, A., RAPTOPOUlOU, C.P., TERZIS, A., PERLEPES, S.P. eta VICENTE, R. 2001. «Defective DoubleCubane, Tetranuclear Manganese(II) and Cobalt(II) Complexes with Simultaneous $\mu 1,1$-Azido and $\mu$-O Bridges». European Journal of Inorganic Chemistry, 1567-1574.

[4] AKO, A.M., HEWITT, I.J., MEREACRE, V., CLÉRAC, R., WERNSDORFER, W., ANSON, C.E. eta POWELL, A.K. 2006. «A Ferromagnetically Coupled Mn19 Aggregate with a Record S = 83/2 Ground Spin State». Angewandte Chemie International Edition, 45, 4926-4929.

[5] MURUGESU, M., HABRYCH, M., WERNSDORFER, W., ABBOUD, K.A. eta CHRISTOU, G. 2004. «Single-Molecule Magnets: A Mn25 Complex with a Record S $=51 / 2$ Spin for a Molecular Species». Journal of the American Chemical Society, 126, 4766-4767.

[6] MILIOS C.J., VINSLAVA, A., WERNSDORFER, W., MOGGACH, S., PARSONS, S., PERLEPES, S.P., CHRISTOU, G. eta BRECHIN, E.K. 
2007. «A Record Anisotropy Barrier for a Single-Molecule Magnet». Journal of the American Chemical Society, 129, 2754 - 2755.

[7] AFFRONTE, M., LASJAUNIAS, J.C., WERNSDORFER, W., SESSOLI, R., GATTESCHI, D., HEATH, S.L., FORT, A. eta RETTORI, A. 2002. «Magnetic ordering in a high-spin Fe19 molecular nanomagnet». Physical Review B, 66, 064408-1 - 064408-7.

[8] NEESE, F. eta PANTAZIS, D.A. 2011. «What is not required to make a single molecule magnet». Faraday Discussions, 148, 229-238.

[9] ISHIKAWA, N., SUGITA, M., ISHIKAWA, T., KOSHIHARA, S.-Y. eta KAIZU, Y. 2003. «Lanthanide Double-Decker Complexes Functioning as Magnets at the Single-Molecular Level». Journal of the American Chemical Society, 125, 8694-8695.

[10] KOIKE, N., UEKUSA, H., OHASHI, Y., HARNOODE, C., KITAMURA, F., OHSAKA, T. eta TOKUDA, K. 1996. «Relationship between the Skew Angle and Interplanar Distance in Four Bis(phthalocyaninato)lanthanide(III) Tetrabutylammonium Salts ([NBun4] [LnIIIPc2]; Ln = Nd, Gd, Ho, Lu)». Inorganic Chemistry, 35, 5798-5804.

[11] RINEHART, J.D. eta LONG, J.R. 2011. «Exploiting single-ion anisotropy in the design of f-element single-molecule magnets». Chemical Science, 2, 2078-2085.

[12] HABIB, F., BRUNET, G., VIERU, V., KOROBKOV, I., CHIBOTARU, L.F. eta MURUGESU, M. 2013. «Significant Enhancement of Energy Barriers in Dinuclear Dysprosium Single-Molecule Magnets Through ElectronWithdrawing Effects». Journal of the American Chemical Society, 135, 13242-13245.

[13] GOODWIN, C.A.P., ORTU, F., RETA, D., CHILTON, N.F. eta MILLS, D.P. 2017. «Molecular magnetic hysteresis at 60 kelvin in dysprosocenium». Nature, 548, 439-442.

[14] a) LIU, J., CHEN, Y.-C., LIU, J.-L., VIERU, V., UNGUR, L., JIA, J.-H., CHIBOTARU, L.F., LAN, Y., WERNSDORFER, W., GAO, S., CHEN, X.-M. eta TONG, M.-L. 2016. «A Stable Pentagonal Bipyramidal Dy(III) Single-Ion Magnet with a Record Magnetization Reversal Barrier over 1000 K». Journal of the American Chemical Society, 138, 5441 - 5450; b) CHEN, Y.-C., LIU, J.-L., UNGUR, L., LIU, J., LI, Q.-W., WANG, L.-F., NI, Z.-P., CHIBOTARU, L.F., CHEN, X.-M. eta TONG, M.-L. 2016. «SymmetrySupported Magnetic Blocking at $20 \mathrm{~K}$ in Pentagonal Bipyramidal Dy(III) Single-Ion Magnets» Journal of the American Chemical Society, 138, 28292837. 